\title{
UMA PERSPECTIVA DECOLONIAL NA ABORDAGEM DA CONSTRUÇÃO DA RESISTÊNCIA E MOBILIZAÇÃO DAS COMUNIDADES DE JURUTI VELHO EM FACE DO ADVENTO DA ALCOA EM SEU TERRITÓRIO, ESTADO DO PARÁ, AMAZÔNIA, BRASIL ${ }^{1}$
}

\author{
Lindomar de Jesus de Sousa Silva ${ }^{2}$ \\ Maurílio de Abreu Monteiro ${ }^{3}$ \\ Lílian Regina Furtado Braga ${ }^{4}$ \\ Tânia Nazarena de Oliveira Miranda ${ }^{5}$
}

\begin{abstract}
RESUMO
As comunidades de Juruti Velho, no oeste paraense, desenvolveram um processo de resistência e mobilização em defesa dos seus direitos tradicionais e territoriais frente ao advento da mineradora norte-americana Aluminum Company of América (ALCOA). Esse processo pode ser lido na perspectiva da decolonização, na medida em que foi desencadeado pelas comunidades, tendo como substrato os direitos territoriais, a ancestralidade, a relação com natureza e um modo socioeconômico não orientado pelos valores da sociedade capitalista. A resistência ocorreu a partir da organização comunitária, do puxirum, e da conexão com um contexto marcado pela validação dos direitos tradicionais e territoriais na constituição cidadã (1988), na ratificação da Convenção 169 da OIT, de junho de 1989, e na Convenção sobre a Diversidade Biológica (CDB). O presente artigo foi baseado em pesquisa de campo e foca nos processos que conduziram essas comunidades a obterem da empresa e do Estado o reconhecimento da sua tradicionalidade e dos seus direitos territoriais, passando a participar dos resultados da lavra com autonomia, da gestão dos recursos recebidos pela sua própria entidade e da titulação coletiva do PAE Juruti Velho, com o repasse pelo Incra do Contrato de Concessão de Direito Real de Uso (CCDRU). Concluímos que esse processo constitui um importante exemplo de resistência ao poder econômico e político, como também a reconfiguração do espaço e sua interiorização da submissão a um modelo colonial. Juruti Velho insere-se dentro de um contexto de desconstrução de saberes coloniais e afirmação de uma perspectiva decolonial.
\end{abstract}

Palavras-chave: Comunidade. Grande Projeto. Decolonial.

\section{ABSTRACT}

The communities of Juruti Velho, in western Pará, developed a process of resistance and mobilization in defense of their traditional and territorial rights in the face of the advent of the American mining company Aluminum Company of America (Alcoa), which intensified in the early 2000s. The process

\footnotetext{
${ }^{1} \mathrm{O}$ presente texto tem origem na pesquisa que resultou nos trabalhos de pesquisas de Lindomar Silva (2014), Tânia Miranda (2019) e Lilian Braga (2020), referentes ao processo ocorrido em Juruti Velho, situado no extremo oeste do estado do Pará, região conhecida como Baixo Amazonas.

${ }^{2}$ Sociólogo, D.Sc. em Desenvolvimento Sustentável do Trópico Úmido, pesquisador da Embrapa Amazônia Ocidental, Manaus, AM.E-mail: lindomar.j.silva@embrapa.br - https://orcid.org/0000-0002-4816-486X

${ }^{3}$ Professor, doutor em Desenvolvimento Sustentável do Trópico Úmido pelo Núcleo de Altos Estudos Amazônicos (NAEA) da UFPA, professor e pesquisador do Programa de Pós-Graduação Dinâmicas Territoriais e Sociedade na Amazônia (PDTSA) da Universidade Federal do Sul e Sudeste do Pará (UNIFESSPA) e do Programa de Pós-Graduação em Desenvolvimento Sustentável do Trópico Úmido. E-mail: maurilio.monteiro@unifesspa.edu.br- https://orcid.org/0000-0002-0494-1751

${ }^{4}$ Mestrando do Programa de Pós-Graduação em Sociologia (PPGSD) e Direito da Universidade Federal Fluminense (UFF) - E-mail: lreginabraga@ hotmail.com - https://orcid.org/0000-0002-8596-6773

5 Antropóloga, Dra.Sc em Ciências Humanas - Sociologia - E-mail: taniamiranda18@yahoo.com.brhttps://orcid.org/0000-0002-7170-5126
} 
can be read from the perspective of decolonization, insofar as this process was triggered by the communities having as substrate the traditionality, the territory, the people-nature relationship and a socioeconomic mode not guided by the capitalist system. Resistance based on factors related to strategies for experiencing and overcoming personal and collective limitations: community organization and puxirum, in connection with a context marked by the validation of traditional and territorial rights in the citizen's constitution (1988), the ratification of Convention 169 of the ILO, of June 1989 and the Convention on Biological Diversity (CBD) and others that started to give security and legitimacy to the demands of the traditional Amazonian community, in particular. This article focuses on the process that supported the formation of resistance and mobilizations that led communities to sui generis victories in the history of relations between communities and large mining companies in the Amazon, in the period spanning 2000 to 2010. These communities obtained, from its organization, mobilizations and articulations, the condition of going from invisibility to the negotiating table with Alcoa, imposing the company and the state the recognition of its traditionality and its territorial rights, starting to participate in the mining results, with full autonomy over the management of the resources received by its own entity and the collective title of the PAE Juruti Velho, with the transfer by Incra of the Real Use of Rights Concession Contract (CCDRU). We conclude that this process constitutes an important example of resistance and confrontation with economic and political power, as well as the attempt to reconfigure the space and its interiorization of submission to a colonial model, that is, the action of the communities of Juruti Velho, inserts within a context of deconstruction of colonial knowledge and affirmation from a decolonial perspective.

Keywords: Community. Great Project. Decolonial.

Data de submissão: 05.10 .2020

Data de aprovação: 09.11.2020

\section{INTRODUÇÃO}

O presente artigo apresenta os fatores que fundamentaram a luta das comunidades tradicionais na região de Juruti Velho, município de Juruti, Oeste paraense no período de 2000 a 2010, com o advento do processo de instalação da mina de exploração de bauxita pela Aluminum Company of America (Alcoa).

A Alcoa e o Estado brasileiro adotaram a mesma postura de invisibilizar as comunidades tradicionais, desconsiderando a ancestralidade e os direitos territoriais adquiridos ao longo de uma extensa história de convívio coletivo e interação com o ecossistema, que justificou a intervenção da Amazônia pelo governo militar durante o período de 1964 a 1985 e que reverbera até os dias atuais ${ }^{6}$.

Ocorre que as comunidades de Juruti Velho não aceitaram a imposição empresarial e estatal e passaram a construir um intenso processo de mobilização e organização que foi capaz de legitimar a sua ancestralidade e os seus direitos territoriais.

O presente artigo busca fazer uma análise focada nos fatores internos que fundamentaram as mobilizações e resistências das comunidades frente aos avanços das estruturas capitalistas e seus arcabouços ideológicos, que são as vivências comunitárias enquanto organização coletiva que definem estratégias e ações sobre determinado território, e

\footnotetext{
${ }^{6}$ A imagem da Amazônia como um espaço vazio ganha a condição de campanha publicitária durante o Governo Médici sob o slogan "Amazônia, terras sem homens, para homens sem terra”. Para Morbach (2001, p. 4), o vazio se constituiu em um elemento que "permeia magistralmente as elaborações sobre o Mito, funcionando de maneira exemplar, ora como garantia de sucesso aos projetos de ocupação, ora para esconder as reais intenções dessas ações", e os "militares estarão empenhados em descrever esse vazio como esperança, como possibilidade, como um novo lugar: a partir do vazio, tudo pode ser construído".
} 
o puxirum $^{7}$, forma de cooperação que permite a superação das limitações individuas e coletivas, e ao mesmo tempo introjeta, na esfera pessoal e familiar, a consciência, visto que somente a organização coletiva amplia a possibilidade de conquistas do bem-estar individual e comunitário.

A comunidade e o puxirum, como dois lados da mesma moeda, foram as bases para a construção de um movimento capaz de unificar os comunitários de Juruti Velho em torno da defesa dos seus direitos territoriais, resistindo a toda tentativa de cooptação e divisão realizada pela Alcoa. Os fatores internos também se somaram às condições presentes no contexto nacional e internacional, como a constituição de 1988, a ratificação da Convenção 169 da OIT, de junho de 1989, a convenção sobre a diversidade biológica (CDB) e outras conquistas que passaram a dar legitimidade e respaldo às lutas e reinvindicação das comunidade tradicionais, como também permitiram às autoridades e à própria sociedade maior compreensão de questões relacionadas às terras tradicionalmente ocupadas, à identidade, aos direitos territoriais, à ancestralidade e à relação entre as populações humanas e a biodiversidade.

Para a garantia desse processo, o Instituto Nacional de Colonização e Reforma Agrária (Incra) teve de enfrentar duas questões altamente relevantes: a ocupação de um território arrecadado pela União, que lhe deveria, por força legal ${ }^{8}$, ser destinado; e o requerimento de lavra mineral de bauxita para a mesma unidade locacional. A comunidade apresentou pedido de regularização fundiária do território ocupado tradicionalmente ${ }^{9}$, nascedouro do Projeto de Assentamento Agroextrativista Juruti Velho (PAE - Juruti Velho). O Departamento Nacional de Produção Mineral (DNPM) concedeu direito de lavra à Alcoa na área ocupada pelas comunidades que se organizavam em torno do Lago Juruti Velho, com operação licenciada pela Secretaria Executiva de Ciência, Tecnologia e Meio Ambiente do Estado do Pará.

\footnotetext{
${ }^{7}$ O puxirum é uma prática dos comunitários da Vila de Juruti Velho que é definida por Galvão (1955, p.37) como o trabalho "cooperativo nas roças, através dos puxirões, em que um roceiro convida as famílias vizinhas para ajudá-lo, é outro traço que induz maior solidariedade" entre moradores da região amazônica. Para Miranda (2019, p. 128), é uma forma "singular de trabalho, que preza pelo coletivo, organizado por uma família ou por uma pessoa visando à economia de tempo e melhores resultados com determinada atividade ou tarefa, que de outra forma levaria dias para ser terminada" sendo que, no caso de Juruti Velho, o puxirum pode ser convocado em "diversas ocasiões, principalmente para cumprir tarefas consideradas mais árduas ou urgentes" como: "fazer a roça; produzir a farinha; abrir picadas, caminhos e estradas; limpar terrenos para realização de festas e torneios de futebol como forma de angariar dinheiro; ou ainda na construção de casas, barracões, igreja, casa de farinha, etc.”. Nesse sentido, o puxirum para as comunidades de Juruti Velho é mais de que prática de superação das limitações das pessoas e comunitários, é uma atitude de construção do bem-estar em todas as suas dimensões. A palavra que melhor traduz a ideia do puxirum para os não comunitários e moradores de Juruti Velho é mutirão, porém os estudos empíricos permitem afirmar que o puxirum vai de simples associação voluntária de um só dia, como descreve Russo (2007, p.199) ao resgatar a origem da palavra na língua "nhengatu" e que, remetendo ao Brasil Colônia, significa "reunião de esforços em prol de um objetivo comum". Ele está na constituição e manutenção de uma forma rememoração da ancestralidade e tradicionalidade, como pontuou o depoimento de um comunitário a Lopes: "puxirum é como os índios faziam, é como a gente chama, quando vai todo mundo trabalhar em um local na comunidade". (LOPES, 2012, p. 112).

${ }^{8}$ Constituição Federal: Art. 188. A destinação de terras públicas e devolutas será compatibilizada com a política agrícola e com o plano nacional de reforma agrária. $\S 1^{\circ}$ A alienação ou a concessão, a qualquer título, de terras públicas com área superior a dois mil e quinhentos hectares a pessoa física ou jurídica, ainda que por interposta pessoa, dependerá de prévia aprovação do Congresso Nacional. § $2^{\circ}$ Excetuam-se do disposto no parágrafo anterior as alienações ou as concessões de terras públicas para fins de reforma agrária.

9 Decreto 6040/2007: Art. 3ํㅜㄹ Para os fins deste Decreto e do seu Anexo compreende-se por: I - Povos e Comunidades Tradicionais: grupos culturalmente diferenciados e que se reconhecem como tais, que possuem formas próprias de organização social, que ocupam e usam territórios e recursos naturais como condição para sua reprodução cultural, social, religiosa, ancestral e econômica, utilizando conhecimentos, inovações e práticas gerados e transmitidos pela tradição.
} 
A abordagem que realizamos identifica o processo das comunidades de Juruti Velho como uma ação que pode ser lida dentro do aparato teórico da decolonização ${ }^{10}$ do pensamento, da ação e dos saberes. A decolonização está no fato de a mobilização e a resistência estarem alicerçadas na comunidade e no puxirum, e não em modelos organizativos forjados em outras realidades e tempos históricos, na valorização do conhecimento local, na ancestralidade, tradicionalidade e no território.

Os resultados das mobilizações e resistências das comunidades foram a passagem da invisibilidade para a mesa de negociação com a Alcoa, com o pleno reconhecimento dos seus direitos territoriais e a participação nos resultados da lavra com total autonomia de gerenciamento através de sua própria organização: Associação das Comunidades da Região de Juruti Velho (Acorjuve) ${ }^{11}$.

Além das conquistas junto à empresa, as comunidades conseguiram receber, em 2009, a titulação coletiva do Projeto de Assentamento Agroextrativista Juruti Velho, através do contrato de Concessão de Direito Real de Uso (CCDRU), uma luta de décadas. Todas essas conquistas eram impensáveis em períodos e décadas anteriores.

É evidente que as conquistas impõem novos desafios e questionamentos às comunidades de Juruti Velho e a todos que militam diretamente em movimentos, desenvolvem ações e estudos vinculados aos processos de decolonização e que compreendem que ela não ocorre como um passo de mágica, visto que exige um exercício constante de reflexão, de luta diária e enfrentamento de todos os processos sociais, econômicos, políticos e ideológicos que conduzem à perpetuação das dimensões coloniais. Estas dimensões coloniais estão interiorizadas em muitos agentes sociais, na elite política e econômica, como também em práticas e ações governamentais e institucionais.

O processo de mobilização e conquista das comunidades representou apenas alguns passos em direção à autonomia que, na visão de Paulo Freire (1996, p. 156), é a busca da libertação, emancipação e superação das opressões que restringem ou anulam a liberdade e, como um ensaio de construção de um "ser para si", a busca de condições para a superação da heteronomia, condição de oprimido e alienado ou de "ser para outro". Neste sentido, a luta precisa continuar, diariamente e de modo permanente, até a emancipação integral.

Dado, portanto, às complexidades geradas pelas pós-conquistas das comunidades de Juruti, percebe-se a necessidade de uma análise mais profunda de como os ganhos políticos e econômicos influenciam, limitam ou potencializam os processos de emancipação das

\footnotetext{
${ }^{10}$ Segundo Quintero $(2019$, p. 4), não existe um "consenso quanto ao uso do conceito decolonial/descolonial, ambas as formas se referem à dissolução das estruturas de dominação e exploração configuradas pela colonialidade e ao desmantelamento de seus principais dispositivos", já que no campo dos debates relacionados há autores como Aníbal Quijano, que utiliza descolonialidade, e outros autores que utilizam decolonidade. O autor diz, citando Catherine Walsh, em livro organizado pela autora intitulado Interculturalidad, Estado, sociedad: luchas (de)coloniales de nuestra época (2009), que a "a supressão do "s" não significa a adoção de um anglicismo, mas a introdução de uma diferença no "des" castelhano, pois não se pretende apenas desarmar ou desfazer o colonial".

${ }_{11} \mathrm{O}$ ambiente organizativo constituído nas comunidades serve de base para a formação das associações das comunidades de Juruti Velho, as quais possuem uma estrutura voltada a estimular a participação do conjunto das comunidades. Diante das distâncias e da fragilidade de comunicação, circulação das informações e locomoção de pessoas, a melhor forma de organização foi a constituição de polos englobando comunidades próximas. Esses polos realizam as discussões e apresentam propostas que depois vão ser submetidas às assembleias com representantes das comunidades. O processo de constituição da Acorjuve foi gestado durante todos os processos de mobilização, que iniciaram a partir do ano de 2000, culminando com a sua fundação em 2004 em assembleia que reunia mais de 2 mil pessoas das 45 comunidades que compõem a associação. Essa organização "se estrutura com reuniões nas comunidades, por áreas: Miri, Uxituba, Vila Muirapinima, Maravilha, Pompom, Galileia, Rio Mamuru; reuniões de diretores e conselheiros, assembleias de polos e assembleia geral e ou assembleias informativas quando há necessidade de repasse de informações ou consulta aos moradores a respeito de determinadas questões" (Entrevista com assessora da Acorjuve, em agosto de 2012).
} 
comunidades. Este artigo se limita ao período de construção da resistência e foca no período anterior, nos fatores que foram as bases para a resistência e a mobilização.

Compreendendo que todo esse processo consiste em um ensaio amazônico de construção da autonomia e da emancipação que dialoga diretamente com a concepção decolonial e expõe elementos essenciais para pensar a crítica ao capitalismo, entende-se ser preciso valorizar o conhecimento local e a dimensão étnica das comunidades amazônicas, para a construção de um projeto que ao "haver somado histórias de lutas, de resistência e de propostas de mudança, e ao nutrir-se de experiências locais, às que deverão somarse contribuições provenientes de diversas latitudes, posiciona-se como ponto de partida para estabelecer democraticamente sociedades sustentáveis". (ACOSTA, 2016, p. 40).

\section{FUNDAMENTAÇÃO TEÓRICA}

Para Lander (2005, p. 10), colonização na América ${ }^{12}$, em 1492, é o momento inaugural "dos dois processos que articuladamente conformam a história posterior: a modernidade e a organização colonial do mundo", em que passa a existir uma "organização colonial do mundo" concomitante à "constituição colonial dos saberes, das linguagens, da memória (MIGNOLO,1995) e do imaginário" (QUIJANO,1992), marcado pelo genocídio e etnocídio, que é a "destruição sistemática dos modos de vida e pensamento de povos diferentes daqueles que empreendem essa destruição"(CLASTRES, 1980, p. 83).

A compreensão de Lisboa (2014, p. 503) assinala que a chegada dos europeus no novo continente significou a eliminação das "denominações originais dos povos que aqui viviam há milênios", a ocultação de "toda alteridade" e o início de "uma projeção de si próprios, representando o novo mundo como um continuum da Europa". Isso torna a chegada dos europeus não "uma descoberta", e sim o "encobrimento", a "negação do outro" e a "ocultação da miríade de outridades aqui presentes", o que significa que os "povos, a fauna e a flora [seriam] apenas um substrato a conquistar, explorar, massacrar".

A emergência do "circuito comercial do Atlântico", segundo Mignolo (2005, p. 34), acelerou a economia capitalista, a transformação da "concepção aristotélica da escravidão exigida tanto pelas novas condições históricas quanto pelo tipo humano (por ex. negro, africano) que se identificou a partir desse momento com a escravidão e estabeleceu novas relações entre raça e trabalho".

Em volta deste mesmo pensamento, Santos (2010, p. 14) compreende que a colonização montou uma "gramática social muito grande que atravessa a sociabilidade, o espaço público e o espaço privado, a cultura, as mentalidades e as subjetividades", tornando mais difícil o processo de decolonização.

Neste contexto, as comunidades tradicionais têm resistido e enfrentado a dominação colonial a partir dos seus sistemas de vida que envolvem a relação com os ecossistemas e seus sistemas sociais, econômicos e culturais.

Diegues (2000, p. 82) inicia a construção do conceito de populações tradicionais anotando que são "sociedades que desenvolveram formas particulares de manejo dos recursos naturais que não visam diretamente o lucro, mas a reprodução social e cultural; como também percepções e representações em relação ao mundo natural marcadas pela ideia de associação com a natureza e dependência de seus ciclos”. Desse início de desenvolvimento conceitual, ao

\footnotetext{
${ }^{12}$ Porto-Gonçalves (2005, p. 4) lembra que a América é um “continente sem-nome próprio, ao contrário da Ásia e da África que se deram seus próprios nomes". O nome dado ao "novo mundo" é uma homenagem ao Italiano Vespúcio, que fincando-se nessa vasta faixa de terra, teve "um papel protagônico, subalternizado é certo, sem o qual a Europa não teria acumulado toda a riqueza e poder que concentrou".
} 
pensar comunidades e populações tradicionais na Amazônia, Almeida (2008, p. 30) aponta que a tradicionalidade estaria ligada ao

\begin{abstract}
fator identitário e todos os outros fatores a ele subjacentes, que levam as pessoas a se agruparem sob uma mesma expressão coletiva, a declararem seu pertencimento a um povo ou a um grupo, a afirmarem uma territorialidade específica e a encaminharem organizadamente demandas face ao Estado, exigindo o reconhecimento de suas formas intrínsecas de acesso à terra, que me motivaram a refletir novamente sobre a profundidade de tais transformações no padrão "tradicional" de relações políticas.
\end{abstract}

\title{
1.1. A NECESSIDADE DE SUPERAR OS PARADIGMAS COLONIAIS
}

O grande desafio de movimentos, organizações e comunidades que buscam superar o paradigma colonial é compreender que o projeto modernidade/racionalidade tem noções complementares e harmônicas entre si, o que significa que não há modernidade sem colonialidade. (QUIJANO, 1992).

Para Castro (2019, p. 35), desde o século XXI, observa-se a necessidade de "repensar as transformações econômicas, tecnológicas e comunicacionais que têm produzido efeitos importantes na vida social e ao planeta, e nos instiga a buscar outras epistemologias para compreender e interpretar o nosso tempo". Neste repensar, Lander (2005, p. 17) lembra que:

\footnotetext{
Nesta construção eurocêntrica, desaparece do campo de visão o colonialismo como dimensão constitutiva destas experiências históricas. Estão ausentes as relações de subordinação de territórios, recursos e populações do espaço não-europeu. Desaparece assim do campo de visão a presença do mundo periférico e de seus recursos na constituição do capitalismo, com o qual se reafirma a ideia da Europa como único sujeito histórico.
}

Boaventura de Sousa Santos (2008, p. 102), em seus escritos na "Sociologia das Ausências" (2008), torna "objetos impossíveis em possíveis e com base neles transformar as ausências em presenças”. Desta forma, são possíveis as formas de produção da não existência, que uma vez realizadas "resulta na subtração do mundo e na contração do presente, e, portanto, no desperdício da experiência". (SANTOS, 2008, p. 104).

A perspectiva de pensar a partir da sociologia da ausência permite, como diz Trouillot (1995, p. 82), pensar o que era considerado "impensável" e superar as "alternativas disponíveis" hegemônicas pela estrutura de pensamento, que há muito tempo estabelece as perguntas e respostas.

Com a sociologia da ausência, é possível romper com a perspectiva da monocultura, em que há a produção da não existência, e transformar a ausência em presença; ela também possibilita focar nas experiências invisibilizadas. Para isso, é necessário operar na perspectiva das ecologias e, assim, transformar "um vínculo entre o conhecimento e a experiência (a ecologia como a ciência da experiência transformativa, baseada no reconhecimento da continuidade da mente, do corpo e do mundo)", o que, "por sua vez, tem consequências na maneira como estabelecemos os vínculos entre a natureza e a experiência". (ESCOBAR, 2005, p.67).

A primeira ação voltada a romper com a dominação colonial está na construção de uma epistemologia que denuncie a supressão e valorize "os saberes que resistiram com êxito e investigam as condições de um diálogo horizontal entre conhecimentos". (SANTOS; MENESES, 2009, p.13). Para Santos (1995, p. 508), é preciso guiar-se pela epistemologia do Sul, que significa: "aprender que existe o Sul; aprender a ir para o Sul; aprender a partir do Sul e com o Sul". Considerar a epistemologia a partir do Sul impõe a necessidade de abraçarmos a ecologia dos saberes, como contraposição à lógica da monocultura e a 
"identificação de outros saberes e de outros critérios de rigor que operam credivelmente em contextos e práticas sociais declarados não existentes pela razão metonímica". (SANTOS, 2002, p. 250).

A adoção de uma epistemologia do Sul e a superação do pensamento abissal, o que Santos (2009, p. 45) chama de pensamento pós-abissal, exigem uma "copresença radical", que significa "que práticas e agentes de ambos os lados da linha são contemporâneos em termos igualitários", e há o abandono da "concepção linear de tempo", o "reconhecimento da existência de uma pluralidade de formas de conhecimento além do conhecimento científico". $\mathrm{Na}$ mesma perspectiva, a epistemologia do Sul possibilita "o novo surgimento político de povos e visões do mundo do outro lado da linha como parceiros da resistência ao capitalismo global, isto é, a globalização contra-hegemônica" e "é uma proliferação sem precedentes de alternativas que, contudo, não podem ser agrupadas sob a alçada de uma única alternativa global".

A contribuição do pensamento epistemológico do Sul e da pós-colonialidade permite a construção de alternativas ao colonialismo, e dão às comunidades tradicionais latinoamericanas, em especial, instrumentos para o levante de lutas pautadas pelos conhecimentos ancestrais que sempre foram marginalizados pela matriz colonial e o modelo hegemônico de poder "instaurado desde a conquista, que articula raça e trabalho, espaço e pessoas, de acordo com as necessidades do capital e para o benefício dos brancos europeus". (ESCOBAR 2003,p.62).

No âmbito da contribuição, está a superação da ideia de desenvolvimento como "eixo principal das reflexões teóricas" e que embasou "um conjunto de correntes e debates que buscaram apresentar diagnósticos e propostas de superação da situação de subdesenvolvidos em que se encontravam os países latino-americanos" (SILVA, 2014, p. 20). Para Sachs (2004, p. 26), isso tornou-se uma "armadilha ideológica construída para perpetuar as relações assimétricas entre as minorias dominadoras e as maiorias dominadas".

Para a Amazônia, conforme indica Monteiro (2006, p. 6), a concepção de desenvolvimento semeou a necessidade de "criar estruturas e espaços homogêneos como vetores capazes de impulsionar o desenvolvimento na Amazônia" nas últimas décadas do século passado, dando "um caráter axiomático nas tentativas de modernização de uma área, considerada pelos planejadores como social e economicamente periférica".

Escobar (2007, p. 2), ao analisar o desenvolvimento como matriz orientadora para a evolução de povos e comunidades, diz que ele significa "sacrificar entornos, solidariedades, interpretações e costumes tradicionais, sempre valorizando a assessoria de peritos", já que "não se pode confiar no próprio nariz; tem que confiar nos peritos, que o levarão a um desenvolvimento". É nesse sentido que a corrente do "pós-desenvolvimento, segundo Amaro (2017, p. 82), permite pensar fora do pressuposto do desenvolvimento e afirma o pósdesenvolvimento como o "fim da era do desenvolvimento e o início de uma nova era, liberta das influências negativas de um conceito dominado por intenções geoestratégicas de natureza capitalista, colonialista e patriarcal".

Uma segunda forma do aspecto essencial no pensamento pós-colonial e pósdesenvolvimentista, e a compreensão do lugar onde há particularidades e interações socioeconômicas, ambientais e culturais, contrapõem a ideia que sempre excluiu e negou voz aos grupos e comunidades amazônicas e impôs grandes projetos econômicos.

Compreender o lugar com a ótica pós-colonial permite, como diz Coronil (1997, p. 74), deixar de legitimar e desmontar "a representação da periferia como a encarnação do atraso bárbaro, desmitifica-se a autorrepresentação europeia como a portadora universal da razão e do progresso histórico".

O resgate do lugar, para Escobar (2005, p. 70), possibilita contrapor um dos temas negados pelo desenvolvimento. Nesse sentido, nas palavras do autor: "o desaparecimento do 
lugar está claramente vinculado à invisibilidade dos modelos culturalmente específicos da natureza e da construção dos ecossistemas. Somente nos últimos anos é que percebemos este fato".

Zhouri e Oliveira (2010, p. 445) compreendem o lugar como o principal caminho para resistência e a "fuga da sujeição aos movimentos hegemônicos do capital e a reapropriação da capacidade de definir seu próprio destino".

A perspectiva analítica de Escobar (2005, p. 72) ressalta que é preciso compreender o conhecimento local como "não puro, nem livre da dominação; os lugares podem ter suas próprias formas de opressão e até de terror; são históricos e estão conectados com o mundo através de relações de poder, e de muitas maneiras, estão determinados por elas".

Através das reflexões de Escobar (2005, p. 72), ao adotarmos uma visão pósdesenvolvimentista do lugar ${ }^{13}$ e do conhecimento local, podemos compreender que "os modelos locais da natureza não dependem da dicotomia natureza/sociedade. E ele complementa: "Além do mais, a diferença das construções modernas com sua estrita separação entre o mundo biofísico, o humano e o supranatural, entende-se comumente que os modelos locais, em muitos contextos não ocidentais, são concebidos como sustentados sobre vínculos". Para Descola (1996, p. 14), isso significa compreender que em sociedade de natureza as "plantas, animais e outras entidades pertencem a uma comunidade socioeconômica, sujeita às mesmas regras que os humanos".

Benatti (2008, p. 32), ao tratar do conceito de posse agroecológica, perspectiva de acionamento ao direito de permanência no território amazônico, o desenvolve indicando que:

\begin{abstract}
A finalidade da terra para seringueiros, ribeirinhos, remanescentes de quilombos é inconciliável com a destinação dada pelas grandes empresas mineradoras, empresas agropecuárias e, na maioria das vezes, pelos grandes projetos governamentais. Nesses momentos de conflito, a definição da faixa de terra necessária para que esses segmentos de camponeses desenvolvam suas atividades agroextrativistas, torna-se essencial para estruturar os vínculos de solidariedade e forjar uma coesão social capaz de enfrentar seus adversários, como também para garantir o controle sobre sua área.
\end{abstract}

Destaca-se neste cenário o grau de coesão e solidariedade existente no grupo, tendo em vista o acesso aos recursos naturais e pode ser estrategicamente organizado com a finalidade de atender à necessidade do grupo, assim como vai colocar os limites dessas possibilidades em vista de eventuais conflitos.

Os conceitos levantados acima subsidiam a reflexão sobre as mobilizações e resistência das comunidades de Juruti Velho e permitem olhar tais processos como um ensaio decolonial. Ballestrin (2013, p. 1) considera que a expressão decolonial "não deve ser confundida como mera descolonização", já que a descolonização em "termos históricos e temporais" significa uma "superação do colonialismo" e a decolonialidade procura "transcender a colonialidade, a face obscura da modernidade, que permanece operando ainda nos dias de hoje em um padrão mundial de poder", como também as posições de facetas póscoloniais calcadas num excessivo culturalismo, no eurocentrismo e sob a forte influência pósmoderna de caráter ocidental.

\footnotetext{
${ }^{13}$ Escobar (2005, p. 76) indica que a compreensão do lugar, como também do conhecimento local, é a forma de ter consciência do lugar e de sua especificidade e de dar ao mundo significado (ESCOBAR, 2001), exige lançar mão da etnografia e assim identificar as "resistências ao capitalismo e à modernidade em ambientes diversos", e "tornar visíveis as práticas e os processos que revelavam que havia múltiplas formas de resistência ativa ao próprio desenvolvimento", como diz Castro (2019,p.32). O autor diz que a etnografia evidencia "como as pessoas sempre criam ativamente e reconstroem seus mundos de vida e seus lugares", e tornam "visíveis outras epistemes presentes no universo do conhecimento do mundo, e ainda, as emergentes".
} 
Walsh (2009) argumenta que o termo decolonial, com a retirada do "s" permite a distinção da palavra descolonização em sua concepção costumeira. Sendo assim, Colaço (2012, p. 7) resume a distinção entre a descolonização e o decolonial, dizendo que: "a intenção não é desfazer o colonial ou revertê-lo, ou seja, superar o momento colonial pelo momento pós-colonial", já que sua acepção busca fomentar e "provocar um posicionamento contínuo de transgredir e insurgir.

\section{DESENVOLVIMENTO}

\subsection{A CONSTRUÇÃO DA LUTA DAS COMUNIDADES DE JURUTI VELHO/PA}

$\mathrm{Na}$ logística do desenvolvimento ocidental, a região Amazônica é transformada em um espaço destinado à acumulação do capital e, na busca por acumular o capital, sob o rótulo do desenvolvimento, as comunidades tradicionais são invisibilizadas e transformadas em obstáculos ao progresso, o que justifica a expropriação de territórios e dos recursos naturais, muitas vezes de forma violenta.

A empresa Aluminum Company of America (ALCOA) ${ }^{14}$ chegou em Juruti em 2001, partindo da lógica da invisibilidade e expropriação das comunidades amazônicas. Esse advento é celebrado pelas elites e autoridades locais como o desenvolvimento que acontece e que se justifica pela perspectiva da modernidade capitalista, já que tudo que existia antes do empreendimento está ligado ao "atraso".

A Alcoa, um grande empreendimento capitalista, reivindicou para si um território historicamente habitado por pescadores, agricultores familiares e extrativistas (SILVA, 2014). Dados do Incra (2007) indicam que mais de 60\% da renda familiar destes tem origem em atividades de roça e coleta de produto extrativista, e uma forte economia não monetarizada é identificada nas trocas de produtos extrativos, como caça e pesca, com destinação para o autoconsumo, o que é uma prática "comum nos relatos dos moradores", que têm "Juruti Velho como um lugar comunitário e de uso coletivo". (SILVA, 2014, p. 138).

A implantação da Alcoa em habitat histórico coloca em questão a natureza capitalista versus natureza orgânica, que contrapõe o modelo racional, ocidental de uma grande empresa mineradora (Alcoa) com a tradicionalidade e a necessidade de comunidades cujo território e prática calcada no conhecimento tradicional são a base da vida de milhares de agricultores e extrativistas. (SILVA, 2014).

O lugar onde essa população ribeirinha desenvolve suas relações tem uma fração de 109.000 hectares do território da Gleba Vila Amazônia, destacada e arrecadada pela União. Através do INCRA, este território foi destinado para compor o Projeto de Assentamento Agroextrativista Juruti Velho, definido por Parecer Técnico Multidisciplinar (Proc. INCRA SR-30/STM - 54501.004431/2007-15 - Vol. I, p. 130), com a modalidade de:

assentamento destinado a populações tradicionais, para exploração de riquezas extrativistas, por meio de atividades econômicas viáveis e ecologicamente sustentáveis, introduzindo a dimensão ambiental às atividades agroextrativistas. Tais áreas, de domínio público, serão administradas pelas populações assentadas, através de sua forma organizativa, que receberá a concessão de direito real de uso.

$\mathrm{Na}$ construção da resistência ao projeto da Alcoa, as comunidades realizaram um intenso processo de valorização de sua ancestralidade e tradicionalidade e abriram mão de

\footnotetext{
${ }^{14}$ A criação da Alcoa data de 1888. Atualmente, a empresa opera em mais de 200 localidades em 31 países e é a principal produtora de bauxita, refinamento de alumina, alumínio primário e industrial do mundo (SILVA, 2014).
} 
programas compensatórios e concessões disponibilizadas pela empresa. Elas optaram pela mobilização e resistência, pelo reconhecimento, fortalecimento e garantia dos seus direitos territoriais, sociais, ambientais, econômicos e culturais, como também pelo respeito e valorização a sua identidade, suas formas de organização e suas instituições. Sua pauta mobilizadora no embate com a Alcoa era: 1) A reafirmação de comunidade tradicional (descendentes dos Mundurucu); 2) Direitos a território historicamente habitado; 3) Garantia da coletividade; 4) Autonomia para defender e decidir sobre o futuro. (SILVA,2014, p.163).

A tradicionalidade passou a ser a pedra angular das ações e mobilizações da comunidade. Em ofício enviado e protocolado no dia 22 de março de 2005 ao Secretário Executivo de Ciência, Tecnologia e Meio Ambiente (SECTAM), a Associação das Comunidades da Região de Juruti Velho (ARCOJUVE) apresentou-se como uma organização que congregava "mais de 1.500 associados, representando 45 comunidades, todas situadas na área de influência direta do projeto ALCOA, ocupadas e habitadas imemorialmente por moradores nativos descendentes dos Muirapinima e Munduruku" (SILVA, 2014, p. 194).

Desta forma, as comunidades subverteram a ordem e impuseram a necessidade de serem vistas e ouvidas, e desafiaram um sistema que há mais de 500 anos pratica junto aos territórios, povos e comunidades formas de "extermínio", que vão do "massacre físico ao massacre da caneta" (CASTRO, 2019, p.21), como também, em nome da civilização, impõe a "homogeneização dos comportamentos", a "invisibilidade da identidade étnica" e a "exploração e subalternização" das comunidades tradicionais. A ação de Juruti Velho corrobora com o pensamento de Escobar $(2005$, p. 3), que entende a invocação da "defesa dos territórios ancestrais e a proteção do meio ambiente como as mais notórias formas de resistência em face dos projetos de exploração capitalista dos recursos naturais".

A resistência calcada na tradicionalidade significa "uma consciência de si como grupo distinto, com identidade coletiva própria e formas de organização intrínsecas que não se reduzem à ocupação econômica ou à relação com os meios de produção". (ALMEIDA, 2010, p. 105).

Na história da Amazônia há um conjunto de grandes empreendimentos econômicos e territoriais que tiveram sua legitimidade justificada pela ideia de desenvolvimento e modernização e que sempre prevaleceu sobre os direitos territoriais étnicos das comunidades tradicionais da Amazônia. Exemplos como a Hidroelétrica de Tucuruí ${ }^{15}$, que segundo Corrêa (2009, p. 44), com base no depoimento de lideranças e atingidos pela hidrelétrica e de lideranças do Movimento dos Atingidos por Barragens (MAB) ${ }^{16}$, expõe que os agricultores e ribeirinhos que habitavam as áreas atingidas foram "arrancados de suas terras, expulsos e seduzidos com a promessa de emprego e melhor qualidade de vida para onde iam ser deslocados", com a justificativa de que a barragem viria trazer "desenvolvimento, trabalho, renda e melhor condição de vida para as populações”, fatos que até hoje não se comprovaram.

\footnotetext{
${ }^{15}$ Estima-se que a hidrelétrica "inundou uma área de $2.830 \mathrm{~km}^{2}$ e remanejou mais de 25.000 pessoas, atingindo sete municípios à montante da barragem e mais outros à jusante dela". A CPI das Barragens (1991, p. 05) apud Corrêa (2009, p.44) concluiu que a construção da Usina Hidrelétrica de Tucuruí se "constituiu num abuso de poder do Governo Federal que a projetou e a construiu sem ouvir sua população, além de realizar estudos precários sobre o Impacto Ambiental na área de influência da barragem".

${ }^{16} \mathrm{O}$ Site do MAB informa que o "Movimento dos Atingidos por Barragens tem uma longa história de resistência, lutas e conquistas. Nasceu na década de 1980, por meio de experiências de organização local e regional, enfrentando ameaças e agressões sofridas na implantação de projetos de hidrelétricas. Mais tarde, se transformou em organização nacional e, hoje, além de fazer a luta pelos direitos dos atingidos, reivindica um Projeto Energético Popular para mudar pela raiz todas as estruturas injustas desta sociedade”.
} 
A hidroelétrica de Balbina ${ }^{17}$, na cidade de Presidente Figueiredo, no Amazonas, impactou o modo de vida e os direitos territoriais dos povos indígenas Waimirí Atroarí. Já a Hidroelétrica de Belo Monte ${ }^{18}$ suprimiu territórios e direitos de diversas comunidades que sobreviviam às margens da bacia do Rio Xingu, entre terras indígenas e territórios ribeirinhos. (ARAUJO et al., 2014).

Os exemplos citados e mais uma centena existente têm como consequência a desestruturação da vida econômica e social das comunidades e a desorganização territorial.

\section{RESULTADOS E DISCUSSÃO}

\subsection{A CONSTRUÇÃO DA RESISTÊNCIA EM JURUTI VELHO /JURUTI - PARÁ}

Silva (2014, p. 209) considera a luta e resistência das comunidades de Juruti Velho como um ensaio na luta decolonial, principalmente por conseguir conectar a existência de "elementos internos, ligados à composição orgânica dessas comunidades, que servem de potencialidade, possibilitando a coesão capaz de impulsionar as ações coletivas, dificultado a cooptação e a divisão no interior das comunidades". Para o autor, há dois fatores que são essenciais para a emergência da força comunitária capaz de fazer frente e redefinir as estratégias da Alcoa na região: a vivência comunitária e o puxirum.

O primeiro aspecto é o fator comunidade. Existe na história de Juruti Velho uma longa tradição dos agricultores e extrativistas de se organizarem em comunidade, com objetivo de superar limitações individuais e coletivas; essa também é uma forma de alçarem ganhos socioeconômicos e vivenciarem a religiosidade e a espiritualidade. A ideia de comunidade em Juruti vai de encontro com a ideia de Bauman (2003, p. 10), para quem "não ter comunidade é não ter proteção".

Na história da formação das comunidades de Juruti Velho, há uma forte tradição da organização comunitária, que vem desde os núcleos dos índios Mundurucu e que serviu de base para ação da Igreja Católica ${ }^{19}$ através dos seus missionários. Esse trabalho de evangelização remete a 1818, período de grande presença dos índios Mundurucu no lago Juruti (hoje Lago de Juruti Velho). A ação da igreja nessa fase estava sob a direção missionária com forte presença nos núcleos familiares e comunitários, que tinham uma estreita relação com os indígenas, agricultores e extrativistas e entre suas ações estava a de

\footnotetext{
${ }^{17}$ A Usina Hidrelétrica de Balbina é uma hidrelétrica no rio Uatumã, localizada na parte nordeste do Estado do Amazonas. A localização fica sob a jurisdição do município de Presidente Figueiredo, a $170 \mathrm{~km}$ de Manaus, pela BR/174.

${ }^{18}$ Segundo Costa et al. (2019, p.233), os dados indicaram que ao "final da instalação, uma área com cerca de $515,3 \mathrm{Km}^{2}$ (Tabela 05) foi alvo de supressão vegetal, isto é, aproximadamente 51.530 ha de floresta nativa foram retirados para possibilitar a implantação de todo o sistema e infraestrutura do projeto (barragens, vertedouros, canais, reservatório, casa de força e outros)".

${ }^{19}$ A Igreja Católica constitui um importante organismo da sociedade ocidental, que na história teve um papel essencial em impõe a lógica colonial nas mais diferentes comunidades no interior da Amazônia. Ocorre que as missionárias da congregação das Irmãs Franciscanas de Maristella, que chegaram à região de Juruti na década de 1970, tinham um compromisso "com a realidade concreta do homem e do lugar pelo conhecimento e pela convivência com o povo, na simplicidade e na amizade do dia a dia" (QUEIROZ, 2019, p.129). Essa comunidade de religiosas desenvolveu junto às comunidades uma pedagogia voltada à formação de consciência crítica a partir de um compromisso com a Teologia da Libertação e a Pedagogia do Oprimido, a qual, durante anos, contribuiu para a formação e organização das comunidades, possibilitando, assim, o surgimento de lideranças políticas, sindicais e sociais em Juruti. Nesse sentido, a célula da igreja católica na região de Juruti Velho, no caso a congresso das Irmãs Franciscanas de Maristella, subverte a ordem e assume um compromisso com uma ação que, além de evangelizar, objetivo principal do congresso, conduz a comunidade a uma consciência da necessidade de decolonizar como única via capaz de garantir a emancipação e autonomia.
} 
incentivar a organização dos núcleos comunitários, como condição de organizar o recebimento do sacramento.

O trabalho dos missionários no século XIX definiu territórios comunitários, enraizou e legitimou a Igreja Católica nas regiões, rios e lagos de Juruti como instituição importante para a formação e organização dos agricultores e extrativistas de Juruti Velho. Em muitos casos, a Igreja católica, durante muito tempo, era a única ligação das comunidades com o mundo externo e principal. Ela tinha que "ensinar o povo" que o apego ao solo e à agricultura superam a itinerância do extrativismo, como também contribui na "organização familiar" e no auxílio à organização social. (MACEDO 1884, p. 11 apud MARTINS, 2005, p. 46).

Em 1966, a região de Juruti Velho recebeu os padres Paulo Suess e Pedro Mair e em 1971 as Irmãs Franciscanas de Maristella. Esses religiosos valorizavam o diálogo, a participação e a formação socioeconômica e cidadã de agricultores e extrativistas de Juruti Velho, dando ênfase na interpretação popular da Bíblia e em documentos como o Vaticano II (1962-1965), Medellín (1968), Puebla (1979) e a teologia da libertação, que revelam e/ou retratam as situações de pobreza e injustiças sociais.

É neste contexto que os missionários incentivam e assessoram a formação das Comunidades Eclesiais de Base (CEBs), comunidade para prática religiosa e sociopolítica. É comum nos relatos a lembrança da participação das Irmãs Franciscanas de Maristella e dos Padres em atividades sociais, formação e organização de ações voltadas a buscar os direitos e os bens das comunidades. Para Lopes (2012), as Irmãs Franciscanas prestaram apoio "intelectual" com ampla contribuição na formação e organização das comunidades.

Queiroz (2014, p. 74) expressa como a relação da vida religiosa e a luta social permeou e contribuiu para a formação de uma maior incidência dos comunitários na busca do bem comum e da preservação da natureza: "Aqui a luta pelo direito de permanecer na terra, pela preservação da natureza com sua rica biodiversidade e para garantir que as chamadas políticas públicas cheguem aos que dela necessitam, tornou-se parte da missão".

A ação da Igreja com Padres, Irmãs e agentes pastorais contribuiu diretamente para a consolidação da comunidade enquanto espaço coletivo onde, além do espiritual, organizaram estratégias para ações coletivas voltadas ao bem comum. A liderança abaixo dá o seu depoimento:

\footnotetext{
Liderança: [...] a gente não era respeitado pela ALCOA. Quando eles chegaram aqui em 2000, corriam de alto a baixo [...]. Em reunião da Igreja (Católica), foi decidido verificar o que o pessoal queria aí [...]. Se não me engano, em 18 de fevereiro de 2001 ou 2002 mandamos ofício em nome da Omnia Minérios. Veio um cidadão que representava a Omnia Minérios, um da ALCOA na pessoa do Charles [Charles Ferreira - então Superintendente de Meio Ambiente da ALCOA em Juruti] e a Senior [Senior Engenharia], que prestava serviço para eles. O assunto foi: o que eles estavam fazendo aqui? Quem eram eles? Aí eles foram se identificar [...], explicar que o interesse deles era minerar, exploração de bauxita, que eles não queriam nada do que estava em cima da terra [...]. Aí eu disse: "mas me diga uma coisa, pra vocês chegarem lá onde vocês querem [...] vocês têm que esculhambar tudinho aqui o solo [...], então vocês vão fazer um dano perigoso aí pra nós [...]. O temor que eu tenho aqui é de vocês expulsarem todos esses ribeirinhos daí" (Entrevista concedida ao autor, junho de 2011).
}

Além do fator comunitário, como prática constante e organizada do lugar, existe o puxirum, que nas comunidades de Juruti é uma ação coletiva com forte capacidade de moldar atitudes e mudanças pessoais, possibilitando a coletividade como estratégia de superação dos limites econômicos e sociais típicos das regiões amazônicas.

Nas comunidades tradicionais de Juruti Velho, o puxirum constitui-se em uma ação em que o indivíduo toma consciência de suas limitações e das limitações de outros. O puxirum como prática social possibilita superar ambas, pois se estabelece em clara relação da 
superação, da alienação em relação a sua espécie, à natureza e a si mesmo. Nesse sentido, ele possui uma ação pedagógica e política na medida em que age diretamente sobre o indivíduo, permitindo a sua descoberta, de sua comunidade e "assim descobrindo-se, com eles sofrem, mas, sobretudo, como eles lutam". (FREIRE, 1997, p. 05).

Desta forma, o puxirum é um exercício essencial para fortalecer a comunidade como agente coletivo composto de indivíduos, já que como ação de grupos de famílias e parentes permite colocar as relações vividas em um novo patamar, compreender a situação em que se encontra e, mais do que nunca, aprender a importância da cooperação para alterá-la. Nesse sentido, o puxirum enquanto práxis está em constante movimento direcionado para um objetivo da prática com a prática e/ou ação-reflexão capaz de permitir a compreensão da limitação pessoal e coletiva. Equivale aqui referenciar a expressão cabal de Paulo Freire (1997, p. 71): "Ninguém liberta ninguém, ninguém se liberta sozinho: os homens se libertam em comunhão".

Enquanto a vivência em comunidade constituir um corpo coletivo e moldar a ação política conjunta, o puxirum possibilitará a experiência pessoal dos resultados da cooperação entre indivíduos, o que vai fortalecer a integração do indivíduo ao grupo, e na medida em que os resultados vão surgindo, a participação vai ser tornando mais sólida. A combinação da vivência comunitária e o puxirum é que ambos são duas práticas que fortalecem a ação coletiva e a consciência individual e mostram a importância da cooperação e da solidariedade para a garantia do bem-estar pessoal, familiar e comunitário. Assim, essas duas ações ampliaram e consolidaram o enfrentamento ao estranho, no caso, a Alcoa.

Silva (2014, p. 160) compreende que em Juruti há um encontro de potencialidades internas (comunidade e puxirum) e oportunidades externas no contexto institucional e político, que "interagem e possibilitam o avanço do processo de mobilização e conquistas comunitárias". Essas oportunidades criaram um ambiente e um aparato que favoreceu o avanço da pauta das comunidades. Podemos citar como oportunidades a Constituição de 1988, a ratificação da Convenção 169 da OIT de junho de 1989, a convenção sobre a diversidade biológica (CDB) e outras. Essas oportunidades fazem emergir a compreensão sobre as terras tradicionais, a autodefiniçãa, a ancestralidade, o direito territorial, o modo de vida das comunidades tradicionais e a "estreita relação entre populações humanas e a biodiversidade". (SILVA, 2014, p. 162).

As potencialidades internas e as oportunidades externas, somadas à interação e à ligação das instituições com atuação local, principalmente as Irmãs Franciscanas de Maristella, ampliaram a voz das comunidades ${ }^{20}$, que desde então iniciaram sua articulação com organizações sociais como sindicatos, colônias de pescadores, via campesina e órgãos como Ministério Público Federal e Estadual - instituições essenciais para garantir a fala da comunidade -, como consta em uma das atas de audiência pública (2005), em que o promotor Raimundo Moraes se manifestou da seguinte forma:

\footnotetext{
"Solicito ao presidente da mesa o direito de ceder parte do meu tempo para um representante da comunidade o que foi negado pelo Dr. Paulo Koury que diz não ser possível, pois cada um tem seu espaço de tempo assegurado pelas inscrições”. O promotor Raimundo Moraes diz que "não será isso que irá impedir que aquelas comunidades falem porque a quarta audiência pública em Juruti Velho foi a comunidade que requereu" (AUDIÊNCIA PÚBLICA, Abril/2005).
}

\footnotetext{
${ }^{20}$ Conforme Silva (2014), as primeiras ações voltadas a organizar a resistência das comunidades frente à Alcoa são uma viagem de um grupo de comunitários de Juruti ao município de Barcarena para conhecer os impactos de projetos de mineração junto às comunidades desse município com o apoio das irmãs franciscanas. Entre as tentativas de ampliar a voz das comunidades está o relato da ação das irmãs franciscanas de denunciarem a presença da Alcoa em eventos diocesanos, estadual, regional, nacional e internacional da Igreja Católica, como também o envio de uma carta relatando o que estava acontecendo com o advento da empresa para a embaixada da Alemanha.
} 
Com a capacidade de articular fatores internos e externos e a construção de uma extensa rede de relação com organizações sociais e instituições públicas, as comunidades alcançaram grandes vitórias frente à maior mineradora do mundo (Alcoa). Consideramos que essas vitórias foram alcançadas com uma pauta focada num processo de resistência que pode ser relacionado à histórica luta decolonial das comunidades amazônicas.

Uma das vitórias foi o reconhecimento da tradicionalidade pela gigante da mineração mundial, como também a Acorjuve como entidade representativa das comunidades. Assim diz o comunicado: "A Alcoa já reconheceu as comunidades de Juruti Velho como tradicionais, bem como reconhece que elas detêm direitos e os eventuais danos e prejuízos causados com a instalação da mina serão compensados e amplamente superados" (COMUNICADO DE ESCLARECIMENTO, 2009).

Uma segunda vitória foi o reconhecimento da Acorjuve como entidade representativa das comunidades e como organização capaz de gerir os 1,5\% da participação nos resultados da lavra pelas comunidades. Este é um caso sui generis na relação de uma grande empresa mineradora mundial e as comunidades amazônicas.

Importa destacar que empreendimentos do porte como da mineração de bauxita em Juruti impactam grandemente toda a região de implantação do projeto a partir das intervenções de ordem socioambiental e econômica. São identificados impactos em razão do deslocamento de trabalhadores, mudanças nas condições de vida de famílias camponesas, além da emergência de conflitos, violência e pobreza no entorno dos empreendimentos e aumento das taxas de desmatamento e continuidade na matriz extrativista. (CASTRO, 2017, p. 33).

Os debates propostos pelas comunidades de Juruti Velho se iniciam pela observação da ocupação dos roçados por pessoas estranhas ao território. O bem mais tangível daquelas comunidades era seu roçado, sua casa de farinha, o lago, os furos e os igarapés para pesca. Roland indica que o direito das sociedades tradicionais da África negra parece dar um espaço menos amplo aos direitos individuais do que o direito ocidental moderno. Nesse compasso, questiona o que há de distintivo nestas relações comunitárias:

Essas sociedades, como sabemos, em sua maior parte, têm um modo de produção pluralista. Nossa noção de indivíduo lhe é dificilmente transferível, na medida em que a ela prefere uma organização pluripolar da personalidade (em geral diferenciada no aspecto corporal do ser humano, seu espírito e a força vital que o anima). Plural, a pessoa não está sozinha (a imagem do indivíduo em face do Estado é específica da cultura ocidental moderna). (ROLAND, 2003, p. 272-273).

A comunidade, na sua interconexão, aos poucos vai verificando que uma ocupação silenciosa está ocorrendo e começa a indagar quais as razões para que pessoas estranhas estejam fazendo buracos no meio dos roçados. Experiências como estas se espalham por muitas cidades amazônicas. Eunápio Dutra do Carmo (2017, p. 71) assinala o seguinte:

Entende-se que a visão contemporânea da gestão territorial considera as relações sociais e as tramas de poder e redes no contexto da geoestratégia da economia global, pois o sistema territorial pressupõe diversas manifestações sociais, econômicas, políticas e ambientais e várias escalas, com destaque para as dinâmicas transterritoriais, como são aquelas sentidas no município de Barcarena. Nestes termos, a relação local-global é essencial e imprime o caráter dinâmico, processual, multidimensional e multiescalar da gestão territorial em Barcarena, com a correlação de força dos atores sociais e suas redes, estratégias, temporalidades, linguagens, saberes e poderes. 
Voltando para Juruti Velho, a titulação coletiva da área onde foi criado o Projeto de Assentamento Agroextrativista Assentamento Juruti Velho ${ }^{21}$ era um sonho antigo dos comunitários. A resistência à mineração pressupunha a titulação da área que significava, segundo o diretor da Acorjuve, "o reconhecimento pelo estado e pela empresa do território da comunidade, que tradicionalmente vive no lugar".

$\mathrm{Na}$ luta pelo domínio do território, a organização da comunidade "reivindicava a titulação coletiva de seu território", enquanto a empresa fazia o lobby para a titulação individual. Segundo Gerdeonor Pereira, presidente da Acorjuve, "a empresa queria que a titulação do Incra fosse individual", o que significava para o presidente a intenção da empresa em "manipular" futuramente os moradores do assentamento. (ALMEIDA, 2012, p. 200). A titulação individual facilitaria o processo de cooptação futura e, consequentemente, a redução da resistência. (SILVA, 2014, p. 205).

A titulação coletiva ocorreu em 2009, uma conquista marcante não somente para Juruti, já que foi "a primeira vez que o Instituto Nacional de Colonização e Reforma Agrária (INCRA) concedeu o documento coletivo a populações tradicionais da Amazônia. A entrega ocorreu no próprio assentamento, localizado no município de Juruti, no Oeste do estado Pará" 22 pelo Instituto Nacional de Colonização e Reforma Agrária (INCRA).

\section{CONSIDERAÇÕES}

Desde a colonização, as comunidades amazônicas passaram a sofrer de expropriação por interesses capitalistas e, a partir da segunda parte do século XX, os grandes projetos, concretizados pelas grandes empresas mineradoras, projetos homogeneizadores agropecuários e grandes estruturas de produção de energia e recursos naturais passaram a brotar aceleradamente em detrimento do modo de vida das comunidades amazônicas.

O histórico de invisibilidade de povos e comunidades tradicionais amazônicos, dificilmente não assumindo uma posição nos debates pela democracia, direitos, melhoria da infraestrutura, explica-se pela negativa de reconhecimento da diversidade social e geográfica dos grupamentos encontrados no território brasileiro; assim é ainda pelo "velho costume" top bottom, que caracteriza grandes grupos econômicos que chegam ao interior em busca do lucro fácil com a exploração dos recursos naturais da região, repetindo o modus operandi desenvolvimentista. Para estes grupos transnacionais, os povos tradicionais e originários são incapazes de tomar a frente em ações de reivindicação de melhorias para seus territórios seus modos de vida são considerados 'atrasados' pelos que vêm de fora, o que justifica a operacionalização de seus projetos.

Após 200 anos, no início do século XXI, as comunidades de Juruti foram vitoriosas de forma sui generis e obtiveram a titulação coletiva do PAE Juruti Velho, com o repasse pelo Incra do contrato de Concessão de Direito Real de Uso (CCDRU). Somando as conquistas junto à empresa, esta é uma vitória de uma luta que se arrastava desde a década de 1970.

\footnotetext{
${ }^{21}$ A titulação do PAE Juruti Velho - assentamento criado em 2005 - foi concedida por meio de um Contrato de Concessão de Direito Real de Uso (CCDRU), assinado pelo superintendente regional do Incra no Oeste do Pará, Luciano Brunet, e pelo presidente da Associação das Comunidades da Região de Juruti Velho (Acorjuve), Gerdeonor Pereira (INCRA, 2007). A titulação do PAE Juruti Velho - assentamento criado em 2005 - foi concedida por meio de um Contrato de Concessão de Direito Real de Uso (CCDRU), assinado pelo superintendente regional do Incra no Oeste do Pará, Luciano Brunet, e pelo presidente da Associação das Comunidades da Região de Juruti Velho (Acorjuve), Gerdeonor Pereira (INCRA, 2009).

${ }^{22} \mathrm{Cf}$. portal do Incra, disponível em http://www.incra.gov.br/index.php/noticias-sala-deimprensa/noticias/10455incra-concede-primeiro-titulo-coletivo-a-populacoes-tradicionais-naamazonia . Acesso em: 20 mai. 2014.
} 
Entende-se que há uma singularidade das ações desenvolvidas em Juruti Velho, no sentido de ampliar as discussões para garantir a cultura material e imaterial no que tange aos seus modos de vida locais e as relações com o meio ambiente. Tais elementos foram alimentados pelo trabalho das Comunidades Eclesiais de Base (CEBs), por meio das mulheres religiosas vinculadas à Igreja Católica, que assim criaram um ator coletivo defensor não somente das terras, mas do movimento de preservação dos rios e das águas.

Além desta prioridade de defesa do meio ambiente de forma integral homem-naturezahomem, as comunidades priorizaram debates sobre direitos e cidadania que conseguiram ultrapassar a linha da discussão meramente fundiária. Terra, território, meio ambiente, desenvolvimento sustentável, são agendas introduzidas com a chegada das empresas exploradoras do minério. No entanto, o movimento em Juriti pautou um tipo de desenvolvimento local de interesse da comunidade.

Além da titulação coletiva do PAE Juruti Velho, considera-se a gestão dos royalties, pagos como contrapartida ao direito de lavra da bauxita, realizada pelas comunidades com a finalidade de promover o desenvolvimento do território, um divisor de rios, em Juruti Velho. Do período desta pesquisa até os dias atuais, são praticamente dez anos de atividades da mineradora em Juruti Velho e desta gestão de recursos pelas comunidades. Com isso, pode-se perguntar: quais mudanças ocorreram? De que forma elas afetaram o modo de vida tradicional das comunidades?

Inúmeros são os conflitos em volta da gestão do patrimônio engessado naquele ambiente. Afinal, as instituições de referência nesses rincões são e continuam sendo os movimentos católicos, os sindicatos, partidos progressistas ou à esquerda, organizações não governamentais e os coletivos sociais clássicos: ou isso, ou continuam largados à própria sorte, seguindo suas trajetórias sem quaisquer perspectivas de mudança, sem renovação, com as mesmas lideranças, utilizando os mesmos instrumentos de ação. (MIRANDA, 2019, p. 122).

A pesquisa se centrou no período de construção da resistência e negociação das comunidades contra a maior mineradora de alumínio no mundo. Cabe lembrar que a decolonização é um processo contínuo, que envolve resistência e luta a fatores socioeconômicos, políticas, culturas e ideologias que permanentemente buscam conduzir a recolonização, que seria quando a "natureza insubmissa", apresentada durante o processo de mobilizações, resistência e lutas que levaram a conquistas dos direitos territoriais passa a ser "enfim domada", como o diz Fanon. (2005, p. 212).

O estudo conclui que o processo vivenciado em Juruti Velho constitui uma importante etapa da luta decolonial das comunidades amazônicas, cuja resistência está na valorização dos elementos que foram invisibilizados ao longo da história e pelas instituições capitalistas.

\section{REFERÊNCIAS}

ACOSTA, Alberto. O bem viver: uma oportunidade para imaginar outro mundo. Trad. Tadeus Breda. São Paulo: Editora Elefante, São Paulo, 2016.

ALMEIDA, Alfredo Wagner Berno de. Terras de quilombo, terras indígenas, "babaçuais livres", "castanhais do povo", faxinais e fundos de pastos: Terras tradicionalmente ocupadas. $2^{\mathrm{a}}$ edição. Manaus: PGSCA-UFAM, 2008.

ALMEIDA, Alfredo Wagner Berno de. Agroestratégias e desterritorialização: Direitos territoriais e étnicos na mira dos estrategistas dos agronegócios. In: ALMEIDA, Alfredo Wagner Berno de, et al (org.). Capitalismo Globalizado e recursos territoriais: Fronteiras da Acumulação no Brasil Contemporâneo. Rio de Janeiro: Lamparina, 2010. p. 101-142. 
ALMEIDA, Rogerio. Pororoca pequena: Marolinhas sobre a(s) Amazônia (s) de Cá. Belém: Smith, 2012.

AMARO, Rogerio Roque. Desenvolvimento ou Pós-Desenvolvimento? Des-Envolvimento e ... Noflay. Cadernos de Estudos Africanos. n. 34, p. 55 - 87, jul./ dez. 2017. Disponível em: http://www.scielo.mec.pt/scielo.php?script=sci_abstract\&pid=S1645-

37942017000200005\&lng=en\&nrm=iso\&tlng=pt. Acesso em: 3 ago. 2013.

ARAÚJO, Mayara Moreno Vasconcelos; PINTO, Karina de Jesus; MENDES, Flávio de Ooliveira. A Usina de Belo Monte e os impactos nas terras indígenas. Planeta Amazônia:

Revista Internacional de Direito Ambiental e Políticas Públicas. Macapá, n. 6, p. 43-51, 2014. Disponível em:

https://periodicos.unifap.br/index.php/planeta/article/view/1651/MayaraN6.pdf. Acesso em: Acesso em: 3 ago. 2013.

AUDIÊNCIA PÚBLICA [Ata]. Belém: [s.n.], 20 abr. 2005.

BALLESTRIN, Luciana. América Latina e o giro decolonial. Revista Brasileira de Ciência Política, n. 11m p. 89-117, 2013. Disponível em:

https://www.scielo.br/scielo.php?pid=s010333522013000200004\&script=sci_abstract\&tlng= pt. Acesso em: 3 ago. 2013.

BENATTI, José Heder. Posse Agroecológica e Manejo Florestal: um estudo das concepções jurídicas sobre os apossamentos das populações tradicionais na Amazônia Brasileira, 2018.

CASTRO, Edna. Amazônia na encruzilhada: saque colonial e lutas de resistência. In:

CASTRO, Edna. Territórios em transformação na Amazônia - saberes, rupturas e resistências. Belém: NAEA, 2017.

CASTRO, Edna. Razão decolonial, experiência social e fronteiras epistemológicas Edna Castro (Brasil). In: CASTRO, Edna. Pensamento crítico latino-americano (org.). Edna Castro-São Paulo: Annablume: 2019.

CLASTRES, Pierre. Arqueologia da violência pesquisas de antropologia política. São Paulo: Brasiliense, 1980.

COLAÇO, Thais Luzia. Novas perspectivas para a antropologia jurídica na América Latina: o direito e o pensamento decolonial. Florianópolis: Fundação Boiteaux, 2012.

CORRÊA, Sergio Roberto O. Movimento dos Atingidos por Barragem na Amazônia: um movimento popular nascente de "vidas inundadas". Revista Nera, Presidente Prudente, ano $12, \mathrm{n}^{\circ} .15$, pp. 34-65, jul-dez./2009.

COSTA, Savannah Tâmara Lemos; TEIXEIRA, Deisianne de Souza; FARIAS, Layla Jasmim de Sousa; MARQUIORO, Giovanna Saraiva; ANDRADE, Sarah Maria Santos; SILVA, José Antônio de Castro. Usina hidrelétrica de belo monte: análise multitemporal da produção de energia e impactos ambientais. Revista Brasileira de Energias Renováveis, v.8, n.1, 2019, p. 224- 237. Disponível em: https://revistas.ufpr.br/rber/article/view/55258. Acesso em: 3 ago. 2013. 
CARMO, Eunápio Dutra do. Desastres e tensões em Barcarena à luz de disputas territoriais. Territórios em transformação na Amazônia - saberes, rupturas e resistências - Belém: NAEA, 2017, p. 71.

CORONIL, Fernando. The Magical State. Nature, Money and Modernity in Venezuela. Chicago: Chicago University Press, 1997.

DESCOLA, Philippe. Constructing Nature: symbolic ecology and social practice. In: DESCOLA, Philippe. (Ed.). Nature and Society: anthropological perspectives. London and New York: Routledge, 1996. p. 82-102.

DIEGUES, Antonio Carlos. O mito moderno da natureza intocada. $3^{\mathrm{a}}$ ed, São Paulo, USP, 2000.

ESCOBAR, Arturo. "Culture sits in place: reflections on globalism and subaltern strategies of localization', Political Geography 20, 2001. p. 139-174. Disponível em:

https://citeseerx.ist.psu.edu/viewdoc/download?doi=10.1.1.557.6912\&rep=rep1\&type=pdf. Acesso em: 3 ago. 2013.

ESCOBAR, Arturo. O lugar da natureza e a natureza do lugar: globalização ou pósdesenvolvimento? In: LANDER, Edgardo (org. ). A colonialidade do saber: eurocentrismo e ciências sociais. Buenos Aires: CLACSO: 2005.

ESCOBAR, Arturo. "Mundos y conocimientos de otro modo: El programa de investigación de modernidad/colonialidad latinoamericano". In: Tabula Rasa (1). Bogotá, 2003.

ESCOBAR, Arturo. La Invencíon del Tercer Mundo: construccíon e desconstruccíon del desarrollo. Bogotá: Norma, 2007.

FANON, Frantz. Os condenados da terra. Juiz de Fora: Editora UFJF, 2005.

FREIRE, Paulo. Pedagogia da autonomia: saberes necessários à prática educativa. São Paulo: Paz e Terra, 1996.

FREIRE, Paulo. Pedagogia do Oprimido. 54 a ed. Rio de Janeiro. Paz e Terra. 1997.

GALVÃO, Eduardo. Santos e visagens. Um estudo da vida religiosa de Itá; Amazonas. São Paulo: Companhia Editora Nacional, 1955.

INSTITUTO NACIONAL DE COLONIZAÇÃO E REFORMA AGRÁRIA INCRA/SR-30. Aspectos históricos e socioeconômicos do projeto de assentamento agroextrativista: PAE Juruti Velho. Santarém, ago. 2007. (mimeo).

LANDER, Edgardo. Ciências sociais: saberes coloniais e eurocêntricos. In: LANDER, E. (org.). A colonialidade do saber: eurocentrismo e ciências sociais:

perspectivas latinoamericanas, Buenos Aires: Clacso, 2005. (Colleción Sur Sur)

LISBOA, Armando Melo. De América a Abya Yala - Semiótica da descolonização. R.Educ.Públ. Cuiabá, v.23, n.53/2. p.501-531, maio/ago. 2014. Disponível em: 
https://periodicoscientificos.ufmt.br/ojs/index.php/educacaopublica/article/view/1751. Acesso em: 3 ago. 2013.

LOPES, Luís Otávio Canto. Conflito socioambiental e (re)organização territorial: mineradora Alcoa e comunidades ribeirinhas do Projeto Agroextrativista Juruti Velho, município de Juruti. 2012. Tese (Doutorado em Ciências Econômicas) - Faculdade de Ciências Econômicas, Universidade Federal do Rio Grande do Sul, Porto Alegre, 2012.

MARTINS, Karla Denise. Cristóforo e a Romanização do Inferno Verde: as propostas de D. Macedo Costa para a civilização da Amazônia (1860-1890). 2005. Tese (Doutorado em História) Programa de Pós-Graduação em História, Universidade Estadual de Campinas. Campinas, 2005.

MENESES, Maria Paula. Corpos de violência, linguagens de resistência: as complexas teias de conhecimento no Moçambique contemporâneo. In: SANTOS, Boaventura de Sousa; MENESES, Maria Paula (org.). Epistemologias do Sul. Coimbra: Almedina-CES, 2009. p. $23-73$

MIRANDA, Tânia Nazarena de Oliveira. Recomposição socioterritorial em contexto de mineração: utopia e distopia do PAE Juruti Velho - Pará, Baixo Amazonas. 2019. Tese (Doutorado em Ciências Humanas - Sociologia) - Programa de Pós - Graduação em Sociologia e Antropologia Universidade Federal do Pará, Belém, 2019.

MIGNOLO, Walter. D. A. Colonialidade de cabo a rabo: o hemisfério ocidental no horizonte conceitual da modernidade. In: LANDER, E. (org.). A colonialidade do saber:

eurocentrismo e ciências sociais: perspectivas latinoamericanas, Buenos Aires: Clacso, 2005. (Colleción Sur Sur).

MIGNOLO, Walter.D. The Darker Side of the Renaissance. Literacy, Territoriality and Colonization. Ann Arbor: Michigan University Press, 1995.

MONTEIRO, Maurilio de Abreu. A opção possível e desejável por um novo modelo de desenvolvimento. In: MONTEIRO, Maurílio de Abreu.; CARVALÓ, Dion Márcio. (org.). Desafios na Amazônia: uma nova assistência técnica e extensão rural. Belém: NAEA; UFPA, 2006.

MORBACH, Marise Rocha. A publicidade no período Médici: os efeitos da propaganda de ocupação da Amazônia. In: INTERCOM - Sociedade Brasileira de Estudos Interdisciplinares da Comunicação XXIV Congresso Brasileiro de Ciências da Comunicação, 2001, Campo Grande. Trabalhos Apresentados [...]. Mato Grosso do Sul: UNIDERP, UCDB, UFMS, 2001. Disponível em:

http://www.intercom.org.br/papers/nacionais/2001/papers/NP3MORBACH.PDF. Acesso em: 3 ago. 2013.

PORTO-GONÇALVES. Apresentação da edição em português. In: LANDER, E. (org.). A colonialidade do saber: eurocentrismo e ciências sociais: perspectivas latinoamericanas, Buenos Aires: Clacso, 2005. (Colleción Sur Sur).

QUEIROZ, Ivoneide. O despojamento como elemento essencial na missão. Convergência, Brasília, ano 49, n. 468, p. 63-78, jan./fev. 2014. 
QUEIROZ, Ivoneide. Vida religiosa feminina na Amazônia: contribuições para uma ecologia integral. Caminhos de Diálogo: revista brasileira de diálogo ecumênico e inter-religioso, Curitiba, ano 7, n. 11, p. 187-195, jul./dez. 2019. Disponível em: https://periodicos.pucpr.br/index.php/caminhosdedialogo/article/view/26003. Acesso em: 3 ago. 2013.

QUIJANO, Anibal. Notas sobre a questão da identidade e nação no Peru. Estudos Avançados, São Paulo, v. 6, n. 16, 1992. Disponível em: https://www.revistas.usp.br/eav/article/view/9600/11169. Acesso em: 3 ago. 2013.

QUINTERO, Pablo; FIGUEIRA, Patrícia; ELIZALDE, Paz Concha. Uma breve história dos estudos decoloniais. MASP Afterral, 2019.

ROULAND, Norbert. Nos confins do direito: antropologia jurídica da modernidade. São Paulo: Martins, 2003, p. 272-273.

RUSSO, Kelly. Quando 'outros mundos' se encontram: movimentos indígenas e a construção de uma identidade étnica transnacional no Fórum Social Mundial. Buenos Aires: CLACSO, 2007. Disponível em: http://bibliotecavirtual.clacso.org.ar/ar/libros/campus/mato/Russo.pdf Acesso em: 3 ago. 2013.

SANTOS, Boaventura de Sousa. Epistemologias do Sul. Revista Crítica de Ciências Sociais, Coimbra, n. 80, p. 5-10, mar. 2008. Disponível em:

https://journals.openedition.org/rccs/689\#text. Acesso em: 3 ago. 2013.

SANTOS, Boaventura de Sousa; MENESES, Maria Paula. Epistemologias do Sul. Coimbra, Almedinav CES, 2009.

SANTOS, Boaventura de Sousa. Toward a new common sense: law, science and politics in paradigmatic transition. Nova Iorque e Londres: Routledge, 1995.

SANTOS, Boaventura de Sousa. Para além do pensamento abissal: das linhas globais a um ecologia dos saberes. In: Boaventura de Sousa Santos; Maria Paula Meneses (org.)

Epistemologias do Sul. Coimbra: Almedina-CES, 2009. p. 23-73.

SANTOS, Boaventura de Sousa. Um discurso sobre as ciências. 7. ed. São Paulo: Cortez, 2010.

SANTOS, Boaventura de Sousa. Para uma sociologia das ausências e uma sociologia das emergências. Revista Crítica de Ciências Sociais [Online], 63 | 2002. Disponível em http://journals.openedition.org/rccs/1285; DOI: https://doi.org/10.4000/rccs.1285. Acesso em: 04 ago. 2020.

SACHS, Ignacy. Desenvolvimento: includente, sustentável, sustentado. Rio de Janeiro: Garamond, 2004. 
SILVA, Lindomar de Jesus de Silva. Natureza capitalista versus natureza orgânica: o advento da ALCOA e a mobilização e organização das comunidades de Juruti no BaixoAmazonas. 2014. Tese (Doutorado em Ciência do Desenvolvimento Socioambiental) Programa de Pós-Graduação em Desenvolvimento Sustentável do Trópico Úmido, Núcleo de Altos Estudos Amazônicos (NAEA), Universidade Federal do Pará, Belém/PA, 2014.

TROUILlot, M. R. Silencing the Past. Power and the Production of History. Boston: Beacon Press, 1995.

WALSH, C. Interculturalidad, Estado, sociedad: luchas (de) coloniales de nuestra época. Quito: UASB / Abya-Yala, 2009.

ZHOURI, Andréa; OLIVEIRA, Raquel. Quando o lugar resiste ao espaço: colonialidade e processo de territorialização. In: ZHOURI, Andréa; LASCHEFSKI, Klemens (Org.).

Desenvolvimento e conflitos ambientais. Belo Horizonte: Editora UFMG, 2010, p. 439-462. 